\title{
Correspondence
}

\section{Psychological treatment by psychiatrists?}

\section{DeAR SIRS}

I have read in the Psychiatric Bulletin cogent arguments for and against prescribing by psychiatrists (Birchwood, 1991 and Crammer, 1991). This has encouraged me to respond with some related questions: should psychiatrists give psychological treatments and are they equipped to do so? I would argue that we not only should, but ought to do so, and this has important training implications of concern to the College. Psychiatrists have a useful basic training in biological sciences. Medical training encourages communication and interview skills. We have more sophisticated models of illness-behaviour than physicians, but our medical training gives us an understanding of disease processes, and also of psychopharmacology that psychologists lack.

There are other reasons why it is imperative to keep abreast of new psychological treatments. One has to do with the failure of traditional psychotherapy to address the major problems of psychiatric illness. Some would debate this view but most general psychiatrists I speak to support that notion. The other reason is that the rapid development of psychotropic drugs since the 1950s has not brought about the answer to all psychiatric ills. We have many more drugs but few cures.

On the other hand, there has been an impressive development in behavioural and cognitive therapies for a wide range of conditions including depression, phobic disorders, obsessive-compulsive disorder, marital and sexual problems, hypochondriasis as well as applications to chronic psychotic disorders (Hawton et al, 1989; Stern \& Drummond, 1991).

This sudden expansion in psychological therapy has posed a problem to those of us involved in education and supervision of trainees in psychiatry. How to teach methods one was never taught oneself! It requires humility to learn from younger colleagues and to attend workshops to acquire new methods, but it can be done. After this learning phase, there has to be a phase of carrying out the new techniques in one's own clinical practice: something a busy psychiatrist has plenty of opportunity to do. Thirdly, the methods have to be taught and supervised and in turn to be put into practice.

Behavioural and cognitive techniques require drastic retooling for most traditional therapists and it is likely that those older therapists brought up in that way are unlikely to want to change or to be able to change. In considering the emergence of new theories in science, Thomas Kuhn (1970) states:

"Philosophers of science have repeatedly demonstrated that more than one theoretical construction can always be placed upon a given collection of data. History of science indicates that, particularly in the early stages of development of a new paradigm, it is not even very difficult to invent such alternates. But that invention of alternates is just what scientists seldom undertake except during the pre-paradigm stage of their science's development and at very special occasions during its subsequent evolution. So long as the tools a paradigm supplies continue to prove capable of solving the problems it defines, science moves fastest and penetrates most deeply through confident employment of those tools. The reason is clear. As in manufacture, so in science, retooling is an extravagance to be reserved for the occasion that demands it. The significance of crises is the indication they provide that an occasion for retooling has arrived."

What would the implications be of a failure to retool? The psychiatrist is left with his traditional role of descriptive psychopathology. Some would say this is what he does best and he should stick to his lathe. He could also decide to become a traditional psychotherapist and many take this route. He may be seduced by the big business of the psychopharmacology industry, and even fervently believe that the cure for psychiatric problems is in a pill yet to be developed. He may distract himself from the reality of his poor therapeutic skills by becoming a psychiatrist administrator, and perhaps recent White Paper developments facilitate this move.

If the psychiatrist does not carry out cognitive/ behavioural therapy others will. Nurses have already been successfully taught these skills, and many psychologists are waiting in the wings in this country but are already therapeutically active in the USA. Finally, what role can the College take in all this? Surely if the College can have a Special Interest Section on Philosophy it could have a similar section in Behavioural and Cognitive Psychotherapy. This new section could serve to carry out the training referred to by organising meetings and courses. Let the College be guided by its own motto concerning Wisdom: "Possession of experience and knowledge together with the power of applying them critically or practically" (Oxford English Dictionary).

Springfield Hospital

RICHARD STERN

London SW17 7DJ 


\section{References}

Birchwood, M. (1991) \& Crammer, J. L. (1991) Prescribing by psychologists? Psychiatric Bulletin, 15, 34-35.

Hawton, K., Salkovskis, P. M., Kirk, J. \& Clark, D. M. (1989) Cognitive Behaviour Therapy for Psychiatric Problems. Oxford: Oxford University Press.

Kunn, T. H. (1970) The Structure of Scientific Revolutions. Chicago: The University of Chicago Press.

Stern, R. S. \& Drummond, L. (1991) The Practice of Behavioural and Cognitive Psychotherapy. Cambridge: Cambridge University Press.

\section{Derivation of 'crisis intervention' \\ DeAr SirS}

Your conference briefing (Psychiatric Bulletin, January 1991, 15, 36) quotes Dr Parad as describing the underlying principle of crisis intervention "as embodied by the Chinese pictogram for "crisis' which indicates both danger and opportunity". This neat idea comes from one of the most influential textbooks on Crisis Intervention (Aguilera \& Messick, 1970). Neat it may be, but not strictly accurate.

The English words crisis and opportunity are represented by compound words in Chinese. The word for crisis in Chinese is weiji. The word for opportunity is jihui. Both these words contain the Chinese morpheme $j i$ which cannot easily be translated into English by any single word but can mean something like a fulcrum or lever and from this might come such a meaning as crux or turning-point. Wei means danger, hence weiji danger-crux. Hui means able to, hence jihui crux-able.

It is, perhaps, preferable to turn to the Greek derivation of the English word crisis as a source of

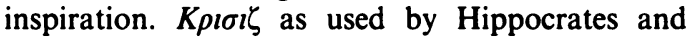
Galen means decision, event, turning-point of a disease (Shorter Oxford Dictionary). The facilitation of decision-making to allow change and growth at this crucial turning point in the life of an individual or family represents the nub of the crisis intervention approach.

Royal Edinburgh Hospital

IAN PULlen

Morningside Terrace

Edinburgh EHIO $5 \mathrm{HF}$

\section{Reference}

Aguilera, D. C. \& Messick, J. M. (1970) Crisis Intervention: theory and methodology, first edition. St Louis: Mosby.

\section{Development of psychiatry in Czechoslovakia}

DeAR SIRS

I read with interest the article by Alan Kerr and Edward Peck (Psychiatric Bulletin, January 1991, 15,
4-6) about psychiatry in Prague. I would like to amplify the historical background relevant to today's Czechoslovakia.

The development of psychiatry reflected the spirit of the time. In the Middle Ages mental illness was regarded as the work of the Devil and was therefore brutally suppressed by the Church. The mentally ill were tortured or ended at the stake. The first mental asylum in Bohemia, run by the Church, was established in Prague in 929. It held 12 patients. The opening of many more hospitals followed.

In the 15th and 16th centuries, with the arrival of the Renaissance and industrial growth, political power shifted to large towns and their inhabitants, especially business men and manufacturers. As a result the first municipal hospital under civic administration and financially supported by the public was opened in the royal town of Znojmo in today's Slovakia. It could accommodate five to 15 mentally ill patients. The fate of the mentally ill remained unsatisfactory. They were left to vegetate in cellars until hunger or infection ended their lives.

In the second half of the 18th century under the influence of a new ideology, the Enlightenment, the Emperor Josef II ordered the building of a new Prague general hospital and so-called Madhouse (Tollhaus), which was situated in the courtyard of the general hospital. Standards of living and hygiene were high and in great contrast to those of previous periods. Patients were admitted with the knowledge of the authorities, since a written confirmation was required. Under the management of Dr Riedel, a Czech, it grew into a centre with a world-wide reputation and one of the best psychiatric hospitals in Europe. Dr Philip Pinel's monograph on therapeutic methods in treatment of the chronically mentally ill became the handbook of nearly all psychiatrists. Dr John Conolly's system of no restraint was widely accepted. Musicotherapy, industrial therapy, hydrotherapy, physical education and school teaching were on prescribing lists and were tailored according to patients' needs. Interestingly 'electrotherapy', using an electromagnetic apparatus, was a recommended treatment.

Further development of Czech psychiatry in Prague was complicated by the division of the Charles University (established in 1348) into the German and Czech parts and the fall of the AustrianHungarian Empire. Dr A. Pick, who described a degenerative process of the brain, worked in the German part of the University. (Incidentally, Albert Einstein worked in the German part of the University, too.)

St Crispin Hospital

Drahomira Allen Duston, Northampton NN5 6UN 